\title{
Modeling and optimization of lipase-catalyzed production of succinic acid ester using central composite design analysis.
}

\begin{abstract}
Esterification of succinic acid with oleyl alcohol catalyzed by immobilized Candida antarctica lipase B (Novozym 435) was investigated in this study. Response surface methodology (RSM) based on a five-level, four-variable central composite design (CCD) was used to model and analyze the reaction. A total of 21 experiments representing different combinations of the four parameters including temperature $\left(35-65^{\circ} \mathrm{C}\right)$, time $(30-450 \mathrm{~min})$, enzyme amount (20-400 mg), and alcohol:acid molar ratio (1:1-8:1) were generated. A partial cubic equation could accurately model the response surface with a R2 of 0.9853 . The effect and interactions of the variables on the ester synthesis were also studied. Temperature was found to be the most significant parameter that influenced the succinate ester synthesis. At the optimal conditions of $41.1^{\circ} \mathrm{C}, 272.8 \mathrm{~min}, 20 \mathrm{mg}$ enzyme amount and 7.8:1 alcohol:acid molar ratio, the esterification percentage was $85.0 \%$. The model can present a rapid means for estimating the conversion yield of succinate ester within the selected ranges.
\end{abstract}

Keyword: Succinic acid; Dioleyl succinate; Enzymatic synthesis; Esterification; Modeling; Central composite design. 